\title{
COMPARATIVE ANALYSIS OF RED OIL AND PALM KERNEL OIL QUENCHING MEDIA FOR LOW CARBON STEEL
}

\author{
Isamotu $^{1 *}$ O.F., Jacob ${ }^{2}$ V.O., Oriaifo ${ }^{2}$ M.A., Raji ${ }^{3}$ K.M., Egu ${ }^{3}$ I.A., Aluko ${ }^{3}$ J.B \\ ${ }^{1}$ Mechanical Engineering, Engineering, Federal University of Technology, Minna, Nigeria. \\ ${ }^{2}$ Mechanical Engineering, Engineering, Federal University of Technology, Minna, Nigeria. \\ ${ }^{3}$ Mechanical Engineering, Engineering University of Abuja, Nigeria.
}

\begin{abstract}
The mechanical properties of low carbon steel $(0.16 \mathrm{C})$ were investigated under two different quenching media (Red oil palm and Palm kernel oil). The properties are: the Tensile strength, strength and hardness of the material. The investi gations centred on un heat treated, water, Red oil palm and Palm kernel oil quenched. Comparisons of the mechanical properties were made. The micr ostructures of the quenched specimen were also examined. The result of the low carbon steel indicated that Red oi 1 palm produced its best properties in tensile strength, impact strength and Hardness value. While Palm kernel oil quenched steel has its best property in yield strength.
\end{abstract}

Keywords: Carbon steel, Quenching media, Heat trea tment, Metallographic examination, Mechanical Prop erties testing, Microstructure and micrograph of speci men.

\section{INTRODUCTION}

Heat treatment is an operation or a combination of operations, involving the heating and cooling of a metal or an alloy in the solid state for the purpose of obtaining certain desirable conditions or properties. Heat treatment is a method used to alter the physical and sometimes chemical properties of a material. Th e most common application is metallurgical. Heat treatments are also used in the manufacture of many other materials, such as glass. ASM (1995). Heat treatment involves the use of heating or chillin $\mathrm{g}$, normally to extreme temperatures, to achieve a desired result such as hardening or softening of a material. ASM (1978). Also it involves: heating a metal to austenitic temperature that is, heat a metal to a temperature at which austenite is formed soaking or holding the metal at that temperature for a period of time and controlled $\mathrm{c}$ ooling of the metal.

Bohumil et al. (2012) and Cavaliere et al. (2016). Qu enching, originated from man's effort to get better th e performance of his operational tools and weapons. The most important development in the quenching came in the $20^{\text {th }}$ century in conjunction with the establishment of transformation diagram, which has made quenching less of an art and more of a science, based on Ause T. (2007).

Quenching is an essential method within the broader field of heat treatment. It constitutes an important manufacturing technology in nearly every market sector. These include: railway, automotive, aerospac e and others Beitz H. (2008). Quenching is used to induce hardness in steel so that it may perform as required in service. It involves heating steel to some temperature above the upper critical temperature, in order to convert it partially or completely to austenite, holding it long enough to ensure the desire austenization, after which cooling is carried out at a rate equal to or faster than the critical cooling rate. The two principal functions of a liquid quenchant is to make possible the hardening of steel by controlling heat transfer during quenching and also to minimize the formation of undesirable thermal and transformat ion gradients which may lead to increase in distortio $\mathrm{n}$ and cracking Ause T. (2007). A medium that is use $\mathrm{d}$ for quenching is called a quenchant.

The process of this heat treatment (quenching) is car ried out first by heating the material and then coolin $\mathrm{g}$ it in water and oil (Red oil palm and Palm kernel o il).

Mechanical properties such as tensile strength, hardn ess, impact energy, microstructure and analysis will be used as criteria to determine the effectiveness of oil chosen as quenching medium for hardening of steel. The steel specimen used was low carbon steel. Low carbon steel is easily available and cheap having all material properties that are acceptable for many applications. 


\section{International Journal of Engineering Applied Sciences and Technology, 2020 \\ Vol. 4, Issue 12, ISSN No. 2455-2143, Pages 67-76 \\ Published Online April 2020 in IJEAST (http://www.ijeast.com)}

Heat treatment on low carbon steel is used to improve ductility, toughness, strength, hardness and tensile strength and to relive internal stress developed in the material. Here basically the experiment of hardness and ultimate tensile strength is done to get idea about heat treated low carbon steel, which has extensive uses in all industrial and scientific fields. The question expected to be answered by this work is: between red palm oil and palm kernel, which among the two will be suitably used as a quenching medium to induce hardness to steel (low carbon steel), producing severity lower than water.

\section{MATERIALS AND METHODS}

The steel materials used for this study is a low-carbon steel obtained from the Department of Metallurgical and Material Engineering, A.B.U Zaria. The chemical compositions of material are shown in Table 3.1. Red oil palm, Palm kernel oil and water are the quenching media used. The mechanical properties investigated were, the tensile strength, impact strength and hardness value. Since standard test procedures were used; standard test specimens were prepared for all the tests. A set of specimens was prepared for conducting pre-heat treatment investigations. A total of six (6) specimens were prepared for each of three tests. Another set was prepared for the investigations conducted two (2) times and the average taken represents the results recorded in the tables.

\subsection{Equipment}

The equipment used in this research includes lathe machine, reheating furnace, hand grinding deck of abrasive paper and rotary wheel for polishing; metallurgical microscope, Hounsfield tensile testing machine used for determining the tensile strength of the quenched samples; Digital hardness machine used to determine the hardness of samples, and Hounsfield Balance impact machine.

2.2 Determination of Physical properties of the Quenchants

\subsubsection{Viscosity}

Apparatus:

Tokinemec Viscometer, beaker, hot plate stirrer and thermometer

Procedure: About $300 \mathrm{~cm}^{3}$ of Red palm oil and Palm kernel oil were poured into the beaker and placed under the rotating needle of the viscometer. The adjusting lever of the viscometer was then lowered till the needle was immersed into about three-quarters of the volume of the oil downwards. The motor of the viscometer was turned on and the reading was recorded. Temperature was varied for 30, 50, 70 and 90 degrees.

2.2.2 Specific Heat Capacity

Apparatus:

Lagged cup calorimeter, digital weighing scale, 500

Watt boiler and Chinese thermometer.

\section{Procedure:}

The empty calorimeter cup was weighted, $\mathrm{m}_{1}=151.84$ grams.

The mass calorimeter cup and Red Oil Palm $\mathrm{m}_{2}=331.01$ grams

The mass of Red oil palm used $\mathrm{m}_{3}=\mathrm{m}_{2}-\mathrm{m}_{1}=($ grams $)$

The empty calorimeter cup was again weighed $\mathrm{m}_{1}=151.84 \mathrm{gram}$

The mass calorimeter cup and Palm kernel oil $\mathrm{m}_{2}=332.95 \mathrm{gram}$

Mass of Palm kernel oil used $\mathrm{m}_{3}=\mathrm{m}_{2}-\mathrm{m}_{1}=($ grams $)$

Power rating of heater used $=500$ Watts

The known mass of the oil was poured into the lagged calorimeter and then the boiler and the thermometer were totally immersed into the oil. The heater was on and left for some time. The initial and final temperature was noted as $t_{1}$ and $t_{2}$. Also the boiler was used as stirrer for even circulation of heat in the oil. Specific heat capacity of the red oil and palm kernel oil was determined at temperature 20,60 and 80 degrees respectively.

$$
\text { From } \mathrm{H}=\mathrm{mc} \theta
$$

Where $\mathrm{H}=$ Amount of electricity used (Watts x time) (C) $\mathrm{m}=$ Mass of oil used, $\mathrm{m}_{3}(\mathrm{~g})$ $\mathrm{c}=$ Specific heat capacity $\left(\mathrm{J} / \mathrm{g}^{\circ} \mathrm{C}\right)$

Oil Palm

Result for Specific Heat Capacity for Red

At $20^{\circ} \mathrm{C}$

$500 \times 18.5=179.17 \times C \times(52-20)$

$9250=5733.44 C$

$C=9250 \div 5733.44$

$C=1.6133 / / g^{\circ} \mathrm{C}$

At $60^{\circ} \mathrm{C}$

$500 \times 10.0=179.17 \times C \times(80-60)$

$5000=3583.4 C$

$C=5000 \div 3583.4$

$C=1.3953 / /^{\circ} \mathrm{C}$

At $80^{\circ} \mathrm{C}$

$500 \times 10.51=179.17 \times C \times(90-80)$

$5255=1791.7 \mathrm{C}$ 


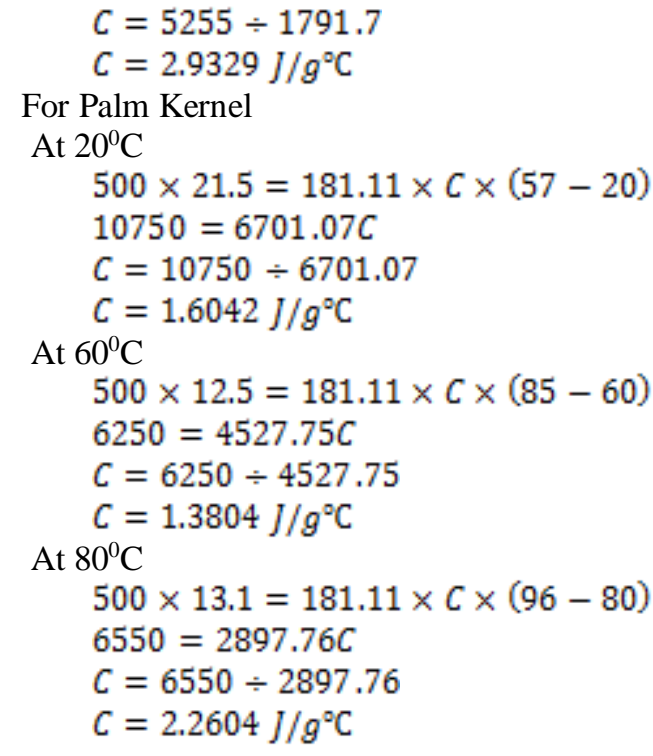

2.2.3 Flash Point

Apparatus:

Chinese thermometer, Hot Plate, Retort stand, Wire mesh and Petri dish

Procedure: Flash point was determined by pouring $10 \mathrm{ml}$ volume of oil into an metallic tin, and then a thermometer hung on the tin and ensured the bulb just dips inside the oil without touching the bottom of the dish and placed on the Hot Plate (open cup method).

\subsubsection{Density}

Apparatus:

$25 \mathrm{~cm}^{3}$ specific gravity bottle, digital weighting machine, water bath, hot plate stirrer, Chinese thermometer and Petroleum ether.

Procedure: Density was determined by thoroughly washing the specific gravity bottle $\left(50 \mathrm{~cm}^{3}\right)$ with detergent water and petroleum ether, dried and weighed. After drying, the bottle was filled with sample and weighed.

Calculation:

Density $=$ Mass of $\mathrm{xcm}^{3}$ of oil $\div$ Volume $\left(\mathrm{xcm}^{3}\right.$ of oil)

$20.2 \mathrm{~g}$

Mass of empty specific gravity + cover $=$

Volume of Specific gravity $=50 \mathrm{~cm}^{3}$

Mass of Red oil palm + bottle + cover at room temperature $=68.30 \mathrm{~g}$

Mass of Red oil palm + bottle + cover at $70^{\circ} \mathrm{C}=$ $67.86 \mathrm{~g}$

Mass of $50 \mathrm{~cm}^{3}$ of Red oil palm at room temp $=68.30$

$-20.0=48.3 \mathrm{~g}$
Density of Red oil palm at room temperature $=48.3 \div 50=0.966 \mathrm{~g} / \mathrm{cm}^{3}$

Mass of $50 \mathrm{~cm}^{3}$ of Red oil palm at $70^{\circ} \mathrm{C}$

$=67.86-20.0=47.86 \mathrm{~g}$

Density of Red oil palm at $70^{\circ} \mathrm{C}$

$=47.86 \div 50=0.9572 \mathrm{~g} / \mathrm{cm}^{3}$

Mass of Palm Kernel Oil + bottle + cover at room temperature $=70.24 \mathrm{~g}$

Mass of Palm Kernel Oil + bottle + cover at $70^{\circ} \mathrm{C}=71.12 \mathrm{~g}$

Mass of $50 \mathrm{~cm} 3$ of Palm Kernel oil at room temperature

$$
=70.24-20.2=50.04 \mathrm{~g}
$$

Density of Palm Kernel Oil at room temperature

$$
\begin{aligned}
& =50.04 \div 50=1.0008 \mathrm{~g} / \mathrm{cm}^{2} \\
& \text { Mass of } 50 \mathrm{~cm} 2 \text { of Palm Kernel Oil at } 70^{\circ} \mathrm{C} \\
& 71.12-20.2=50.92 \mathrm{~g} \\
& \text { Density of Palm Kernel Oil at } 70^{\circ} \mathrm{C} \\
& =51.12 \div 50=1.0184 \mathrm{~g} / \mathrm{cm}^{2}
\end{aligned}
$$

\subsection{Heat Treatment Operations}

All the specimens which were already prepared for the various tests were loaded in the electric furnace, and allowed to heat up to an austenitizing temperatur e of $900^{\circ} \mathrm{C}$. They were allowed to get soaked by maintaining them at this temperature for a period of 30 minutes. The soaked specimens were grouped into three parts. One part was quenched in water. The remaining two parts were quenched in Red oil palm and Palm kernel oil respectively.

2.4 Mechanical Properties Testing

2.4.1 Tensile Strength Determination

The tensile test specimens were mounted one after other on the tensometer as recommended. A small loa $\mathrm{d}$ was initially applied to set the specimen in the grips and the load was increased until failure occurred. The load extension relationship was plotted simultaneous ly. The breaking, yield point and the maximum tensil e loads of the quenched specimens were obtained. The ultimate tensile strength (UTS) and the yield strength were determined from the relationship

$$
\begin{aligned}
& U=\frac{P_{\max }}{A_{0}} \\
& \text { Yield strengt }=\frac{\text { Yield point lood }}{A_{0}}
\end{aligned}
$$

Also, the percentage elongation and the percentage reduction in area were obtained.

Where $\mathrm{P}_{\max }=$ Maximum load applied

$$
\mathrm{A}_{\mathrm{o}}=\text { Original cross sectional area }
$$




\section{International Journal of Engineering Applied Sciences and Technology, 2020 \\ Vol. 4, Issue 12, ISSN No. 2455-2143, Pages 67-76 \\ Published Online April 2020 in IJEAST (http://www.ijeast.com)}

\subsubsection{Hardness Value Determination}

Hardness and other mechanical properties of plain carbon steels increase with the rise in concentration of carbon dissolved in austenite prior to quenching during hardening heat treatment Rajan et al (2014) an d Thelning (2017).

The hardness of the is indicated by the depth of penet ration of the indenter on the steel specimen Ndaliman M.B. (2006). The hardness values of the specimens were determined using a Digital Rockwell Hardness testing machine due to its high accuracy. The Rockwell hardness number is a measure of the depth of penetration of a standard indentor. Bailey F.W.J (1971).Nine scales of hardnes $\mathrm{s}$ are available (A to $\mathrm{K}$ inclusive) but scale $\mathrm{B}$ was employed. A minor load of 10kgf was first applied and the dial indicator set to zero. The load was then increased to $100 \mathrm{kgf}$ (B scale). When the reading of the dial indicator is steady the major load was taken off and the hardness number read off directly from th e dial indicator Bailey F.W.J (1971).The specimens were mounted in bakelite for both handling and proper flatness.

The surfaces were thoroughly polished before samples were tested. The hardness value was recorded in HRB.

\subsubsection{Impact Strength Determination}

The impact strength is the measure of the energy absorbed by the specimen when it failed as a result of the strike on it by the pendulum of the measuring device. The specimen dimensions were as indicated in Table 11. Each of them was placed in the vice of the supported beam. A heavy pendulum mounted on the ball bearing was allowed to strike the specimen after swinging from a height. The material failed at the strike of the pendulum and the energy absorbed by the specimen was recorded.

\subsection{Metallographic Examination}

The as-quenched specimens in various selected quenching media were subjected to metallographic specimen preparation. Metallographic analysis of the as quenched specimen was done in order to reveal the microstructures. Hassan et al. (2009). Microscopi cal examination of metals depends upon the reflectio $\mathrm{n}$ of light from a polished surface, the preparation of the specimen is very important.

\subsection{Grinding:}

The specimen was made at a convenient size for polishing; the surface to be examined contains saw marks and is not perfectly flat. These saw marks were removed and the surface leveled using a fairly coarse file. Care was taken not to overheat the specimen.
When the saw marks was removed, the specimen is washed, dried and subjected to fine grinding on a series of emery papers of increasing fineness, i.e. $120,180,240,320,400$, and 600 grades of emery. This was carried out by placing the emery paper on a flat glass plate and holding the specimen so that the scratches are formed in one direction only. Grinding is continued until the scratched left from the previous grinding operation was removed. The specimen was then swilled with water and dried before being transferred to a finer paper. The grinding on the next emery paper was carried out so that the scratches are at right angles to those of the previous paper. Finally a series of fine scratches is obtained in the 600 grade of emery paper, and after washing and drying the specimen was ready for polishing.

\subsection{Polishing:}

The fine scratch from the 600 grade of emery paper was removed by using polishing powder on selvyt cloths. The selvty cloth was stretched out by attaching it to a rotary disc of a polishing machine. After polishing, the specimen was swilled with water, followed by methylated and finally dried. Drying was conveniently carried out by using a domestic hot air dryer.

\subsubsection{Examination of the polished surface:}

The polished specimen with its 'mirror finish', free from scratches was then examined under the microscope in order to observe cracks, hard constituents which stand out etc. At this stage the microstructure of the metal is not apparent. Light rays from the microscope strike the surface normally to retrace their path back to the eye.

\subsection{Etching:}

In order to examine the microstructure, the metal was etched. Etching involves the selective corrosion of the polished surface, which renders the various constituents visible by a contrast effect. The specimen was immersed in an etching solution $(2 \%$ natal) for a given time, removed swilled with water and meth, and finally dried. It was then ready for microscopical examination.

\section{RESULTS}

Results for the tensile strength, hardness value and impact strength of the specimen which were not heattreated are presented in Table1.The properties of the heat treated specimen are alsopresented in Table2.

Table 3 presents the results of the physical analysis of the quenchants use for this investigation. 
Published Online April 2020 in IJEAST (http://www.ijeast.com)

Table 1: Mechanical Properties of Unheat-treated low carbon steel.

\section{Properties}

Tensile Strength $\left(\mathrm{N} / \mathrm{mm}^{2}\right)$

Yield Strength $\left(\mathrm{N} / \mathrm{mm}^{2}\right)$

Percentage elongation (\%)

Percentage reduction in area $(\%)$

Impact strength $(\mathrm{J})$

Hardness Value (HRB)

\section{Test Specimen}

156.05
145.16
$20 \%$
$62 \%$
47.05
59.05

Table 2: Mechanical properties of heat-treated low carbon steel

\begin{tabular}{lccc}
\hline Properties & Red oil palm quenched & Palm kernel quenched & Water quenched \\
\hline Tensile Strength $\left(\mathrm{N} / \mathrm{mm}^{2}\right)$ & 166.32 & 128.37 & 242.02 \\
Yield Strength $\left(\mathrm{N} / \mathrm{mm}^{2}\right)$ & - & 100.86 & - \\
Percentage elongation $(\%)$ & 15.75 & 23.75 & 10 \\
Percentage reduction in area (\%) & 62 & 71 & 30 \\
Impact Strength (J) & 46.6 & 45.7 & 29.55 \\
Hardness Value (HRB) & 79.5 & 61.2 & 92.45 \\
\hline
\end{tabular}

Table 3: Load-Extension for Low Carbon Steel As-received

\begin{tabular}{llllllllllllll}
\hline Load $(\mathbf{k N})$ & $\mathbf{0}$ & $\mathbf{1}$ & $\mathbf{2}$ & $\mathbf{4}$ & $\mathbf{6}$ & $\mathbf{8}$ & $\mathbf{9}$ & $\mathbf{1 0}$ & $\mathbf{1 2}$ & $\mathbf{1 4}$ & $\mathbf{1 5 . 8}$ & $\mathbf{1 5 . 6}$ & $\mathbf{1 6}$ \\
\hline Extension $(\mathrm{mm})$ & 0 & 0.2 & 0.4 & 0.9 & 1.1 & 1.2 & 1.3 & 1.5 & 1.6 & 1.8 & 2.6 & 2.8 & 3.5 \\
\hline
\end{tabular}

\begin{tabular}{lllll}
\hline $\mathbf{1 8}$ & $\mathbf{1 8 . 2}$ & $\mathbf{1 8}$ & $\mathbf{1 6}$ & $\mathbf{1 2}$ \\
\hline 3.6 & 4.8 & 5.6 & 6.3 & 7 \\
\hline
\end{tabular}

Table 4: Load-Extension for Low Carbon Steel Quenched in Red Oil Palm

\begin{tabular}{|c|c|c|c|c|c|c|c|c|c|c|c|c|c|c|}
\hline Load $(k N)$ & $\mathbf{0}$ & 1 & 2 & 3 & 4 & 5 & 6 & 7 & 8 & 9 & 10 & 12 & 13 & 14 \\
\hline Extension (mm) & 0 & 0.4 & 0.48 & 0.60 & 0.86 & 0.91 & 0.95 & 1.1 & 1.2 & 1.26 & 1.4 & 1.5 & 1.7 & 1.8 \\
\hline
\end{tabular}

\begin{tabular}{lllllllll}
\hline $\mathbf{1 5}$ & $\mathbf{1 6}$ & $\mathbf{1 7}$ & $\mathbf{1 8}$ & $\mathbf{1 9}$ & $\mathbf{2 0}$ & $\mathbf{2 1}$ & $\mathbf{2 2}$ & $\mathbf{2 3}$ \\
\hline 1.9 & 2.1 & 2.5 & 2.8 & 3.2 & 3.5 & 3.8 & 4.8 & 5.5 \\
\hline
\end{tabular}

Table 5: Load-Extension for Low Carbon Steel Quenched in Palm Kernel Oil

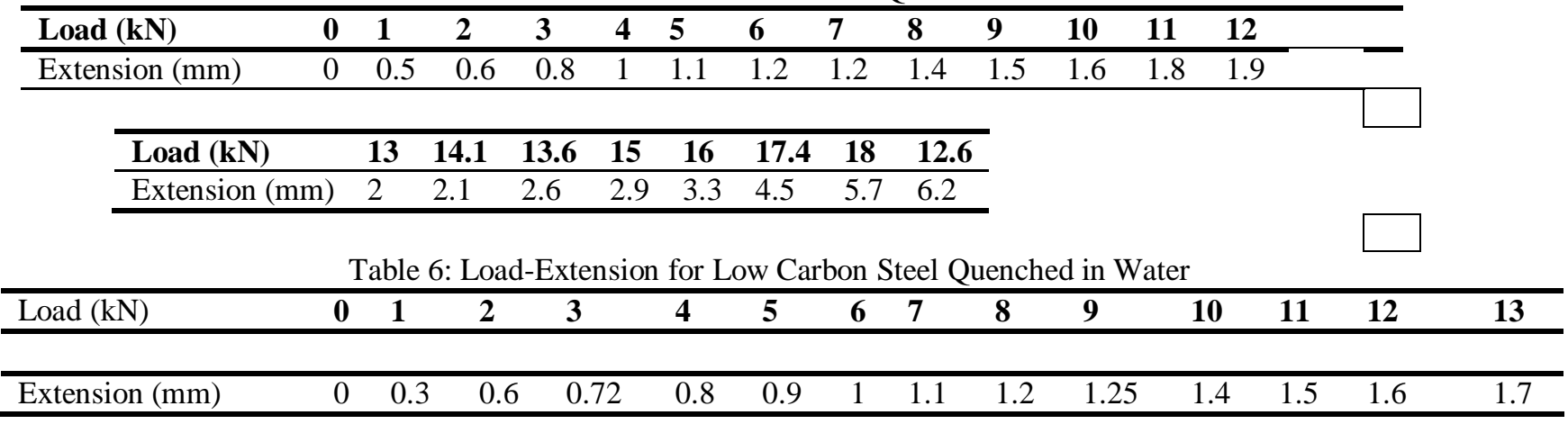

\begin{tabular}{lllllllllllllllllll}
\hline 14 & 15 & 16 & 17 & 18 & 19 & 20 & 21 & 22 & 23 & 24 & 25 & 26 & 27 & 28 & 29 & 30 & 31 & \\
\hline 1.8 & 1.82 & 1.9 & 2 & 2.1 & 2.2 & 2.22 & 2.3 & 2.35 & 2.5 & 2.6 & 2.8 & 3 & 3.2 & 3.4 & 3.6 & 4 & 4.8 & \\
\hline
\end{tabular}


International Journal of Engineering Applied Sciences and Technology, 2020

Vol. 4, Issue 12, ISSN No. 2455-2143, Pages 67-76

Published Online April 2020 in IJEAST (http://www.ijeast.com)

Table 7a: Result for Viscosity Test (Red oil Palm)

\begin{tabular}{ll}
\hline Temperature $\left({ }^{\circ} \mathbf{C}\right)$ & $\mathbf{2 0}$ \\
\hline Viscosity $(\mathrm{cst})$ & 117.64 \\
\hline & \multicolumn{2}{c}{ Table $7 \mathrm{~b}$ : Result for Viscosity Test (Palm Kernel Oil) } \\
\hline Temperature $\left({ }^{\circ} \mathbf{C}\right)$ & $\mathbf{2 0} \quad$ \\
\hline Viscosity $(\mathrm{cst})$ & 128.85 \\
\hline
\end{tabular}

Table 8: Result for Flash Point Test

\begin{tabular}{llc}
\hline Red oil Palm & \multicolumn{2}{c}{$\mathbf{1 6 4}^{\circ} \mathbf{C}$} \\
\hline Palm Kernel oil & \multicolumn{2}{c}{$236^{\circ} \mathrm{C}$} \\
\hline & Table 9a: Result for Density Test $($ Red Oil Palm) \\
\hline Temperature $\left({ }^{\circ} \mathbf{C}\right)$ & Room Temp. & $\mathbf{7 0}^{\circ} \mathbf{C}$ \\
\hline Density $\left(\mathrm{g} / \mathrm{cm}^{2}\right)$ & 0.966 & 0.957 \\
\hline
\end{tabular}

Table 9b: Result for Density Test (Palm Kernel Oil)

\begin{tabular}{lll}
\hline Temperature $\left({ }^{\circ} \mathbf{C}\right)$ & Room Temp. & $\mathbf{7 0}^{\circ} \mathbf{C}$ \\
\hline Density $\left(\mathrm{g} / \mathrm{cm}^{2}\right)$ & 1.0008 & 1.0184 \\
\hline
\end{tabular}

Table 10a: Result for Specific Heat Capacity Test (Red Oil Palm)

\begin{tabular}{|c|c|c|c|}
\hline Temperature $\left({ }^{\circ} \mathrm{C}\right)$ & $20^{\circ} \mathrm{C}$ & $60^{\circ} \mathrm{C}$ & $80^{\circ} \mathrm{C}$ \\
\hline Specific Heat $\left(\mathrm{J} / \mathrm{g}{ }^{\circ} \mathrm{C}\right)$ & 1.6133 & 1.3953 & 2.9329 \\
\hline \multicolumn{4}{|c|}{ Table 10b: Result for Specific Heat Capacity Test (Palm Kernel Oil } \\
\hline Temperature $\left({ }^{\circ} \mathbf{C}\right)$ & $20^{\circ} \mathrm{C}$ & $60^{\circ} \mathrm{C}$ & $80^{\circ} \mathrm{C}$ \\
\hline Specific Heat $\left(\mathrm{J} / \mathrm{g}^{\circ} \mathrm{C}\right)$ & 1.6042 & 1.3804 & 2.2604 \\
\hline
\end{tabular}

Table 11: Methods used in determining the properties

\begin{tabular}{llc}
\hline Properties & Standard specimen type & Mode of Evaluation \\
\hline Hardness & $\phi 8 \mathrm{~mm} \times 16 \mathrm{~mm}$ length & $\begin{array}{c}\text { Rockwell hardness testing machine } \\
\text { Hounsfield Balance Impact } \\
\text { machine }\end{array}$ \\
Tensile Strength & $\phi 8 \mathrm{~mm} \times 45 \mathrm{~mm}$ length & $\begin{array}{c}\text { maching } \\
\text { Hounsfield Tensometer testing } \\
\text { machine }\end{array}$ \\
\hline
\end{tabular}
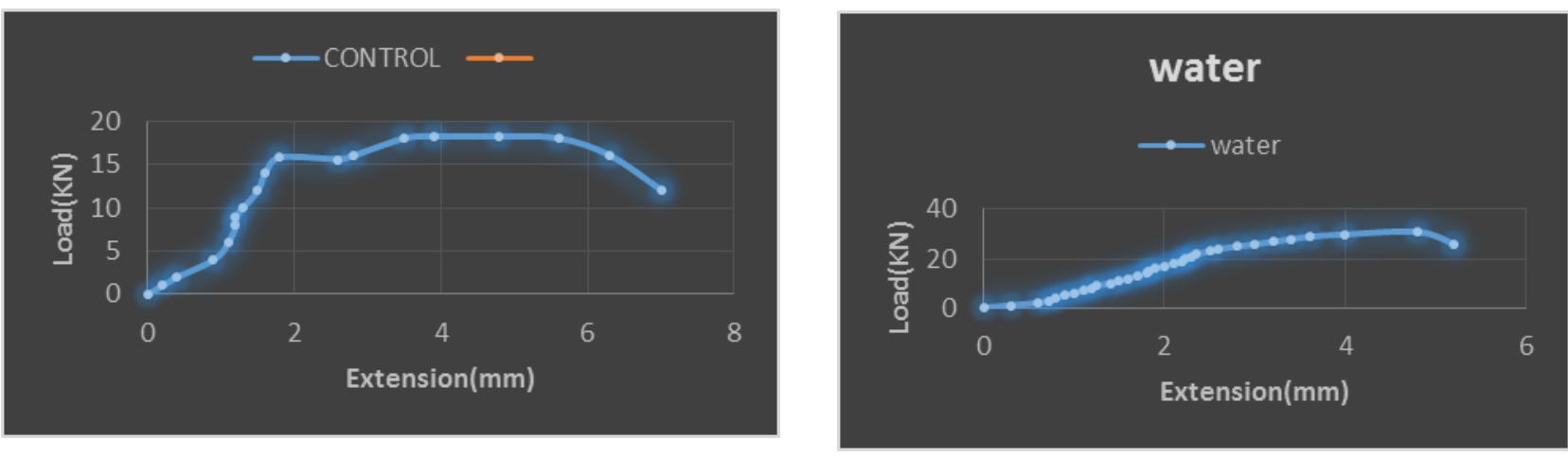

Figure 1

Figure 2

Figure 1: The Load - Extension Graph of the As-Cast Low Carbon Steel 
Published Online April 2020 in IJEAST (http://www.ijeast.com)

Figure 2: Load - Extension Graph of Low Carbon Steel Quenched in Water

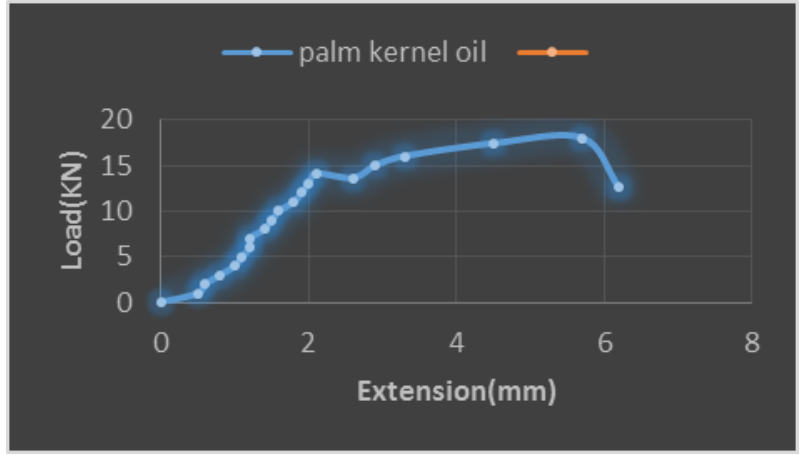

Figure 3

Figure 3: Load - Extension Graph of Low Carbon Steel Quenched in Palm Kernel Oil Figure 4: Load - Extension Graph of Low Carbon Steel Quenched in Red Oil Palm

Figure 5

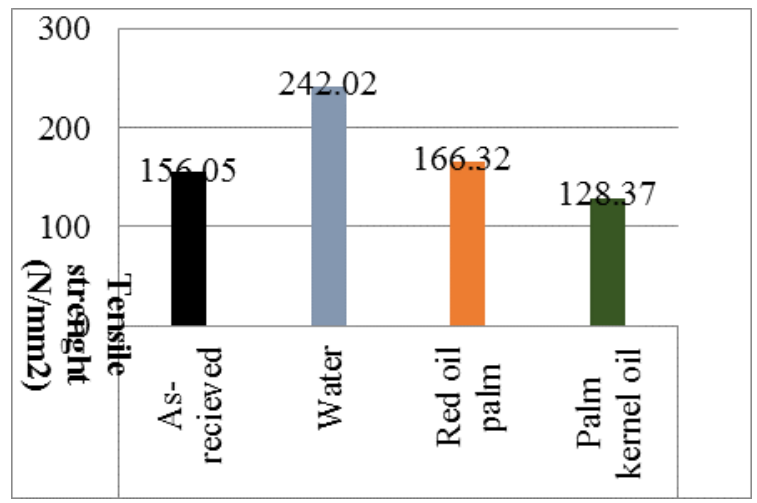

Figure 6

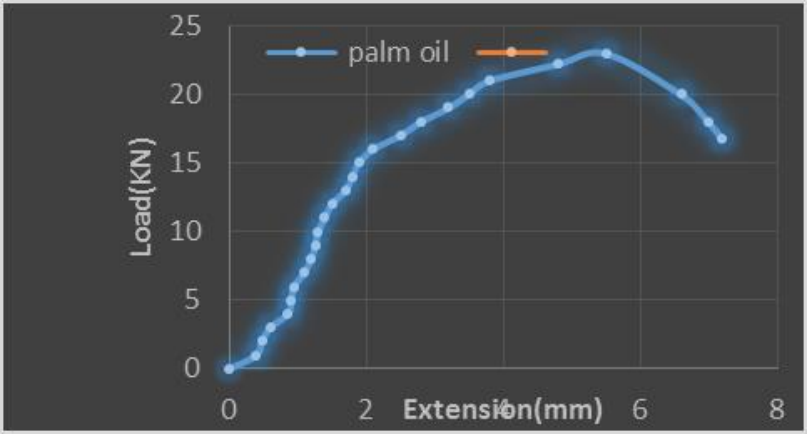

Figure 4

Figure 5: Bar Chart of the Tensile Strength of the the Low Carbon Steel Quenched in Media

Figure 6: Bar Chart of Hardness Values of the Low Carbon Steel Quenched in Media

Figure 7

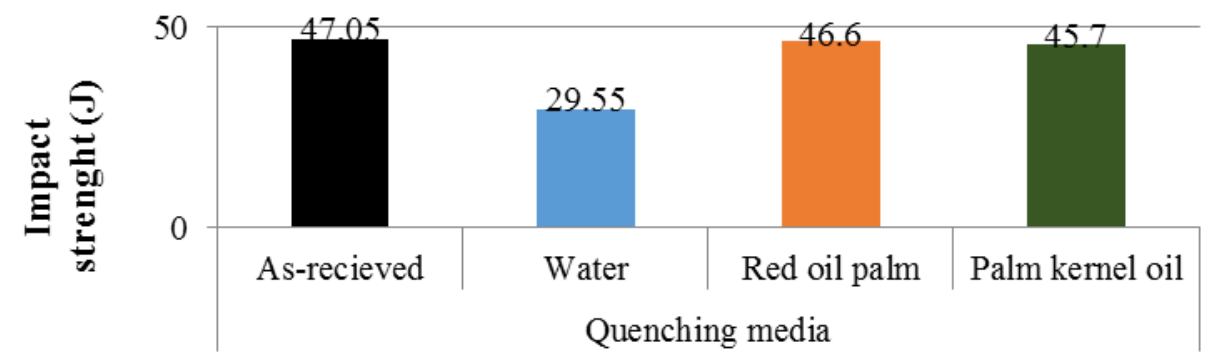

Figure 7: Bar Chart of the Impact Energy of the Low Carbon Steel Quenched in Media 
International Journal of Engineering Applied Sciences and Technology, 2020

Vol. 4, Issue 12, ISSN No. 2455-2143, Pages 67-76

Published Online April 2020 in IJEAST (http://www.ijeast.com)

\section{MICROGRAPHS}

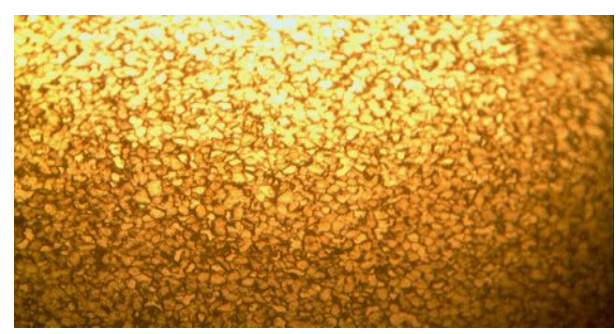

Micrograph 1

Micrograph 1: As-Cast Low Carbon Steel. (X200)

Micrograph 2: As-Cast Low Carbon Steel.

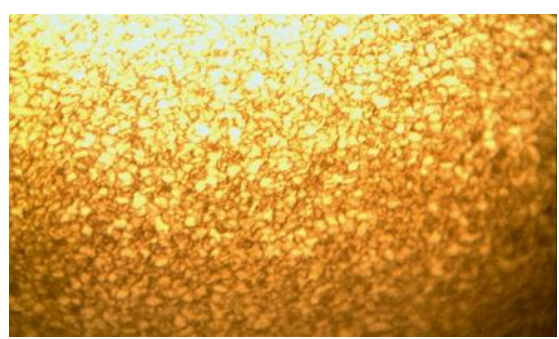

Micrograph 3

Micrograph 3: Low Carbon Steel Quenched in water(X200)

Micrograph4: Low Carbon Steel Quenched Water. (X200)

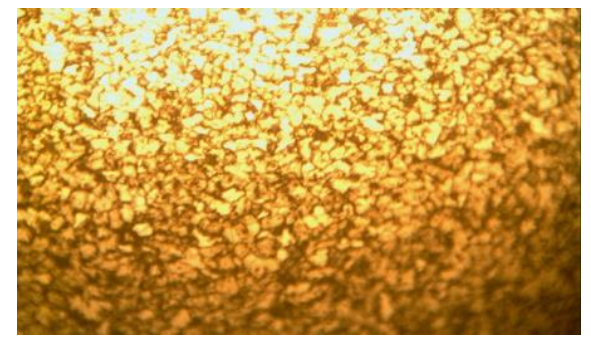

Micrograph 5:

Micrograph 5: Low Carbon Steel Quenched in Red oil palm. (X200)

Micrograph 6: Low Carbon Steel Quenched in Red Oil Palm. (X200)

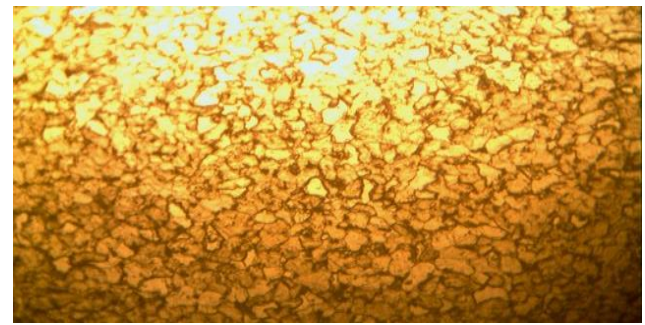

Micrograph 7

Micrograph 7: Low Carbon Steel Quenched in Palm Kernel oil. (X200)

Micrograph 8: Low Carbon Steel Quenched in Palm Kernel oil. (X200)

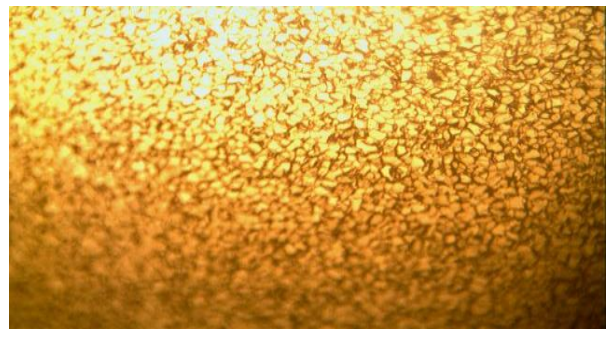

Micrograph 2

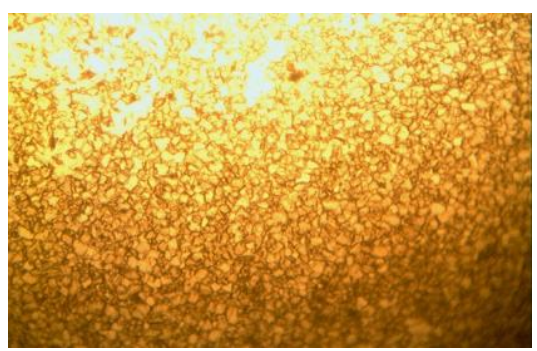

Micrograph 4

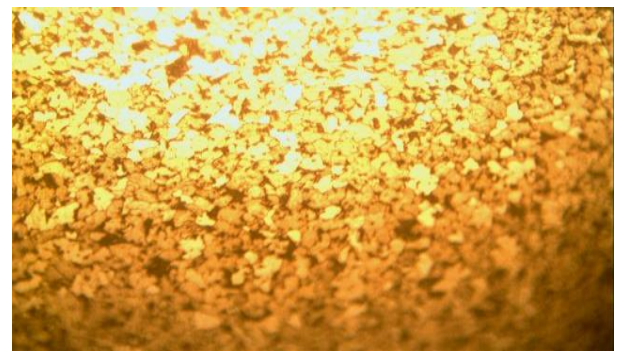

Micrograph 6

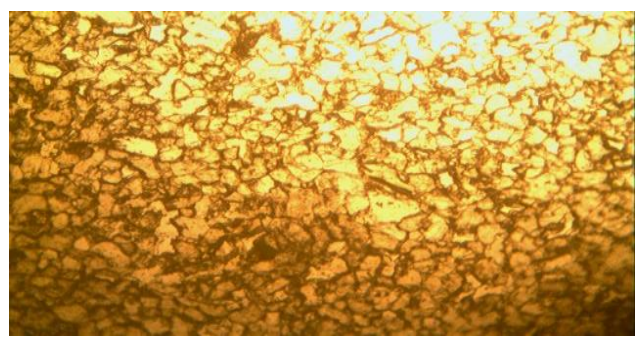

Micrograph 8 


\section{International Journal of Engineering Applied Sciences and Technology, 2020 \\ Vol. 4, Issue 12, ISSN No. 2455-2143, Pages 67-76 \\ Published Online April 2020 in IJEAST (http://www.ijeast.com)}

\section{DISCUSSION OF RESULT}

\subsection{Mechanical Properties of as Quenched Low Carbon Steel}

From the results obtained for low carbon steel the tensile strength value of the specimen increased after quenching in all media except for palm kernel oil which had a lower value of $\left(128.37 \mathrm{~N} / \mathrm{mm}^{2}\right)$. The quenched steel specimen in Red oil palm and Palm kernel oil showed a lower tensile strength compared to water. This is attributable to the fact that water has a higher cooling rate than the Red oil palm and Kernel oil FAO (2015). It is important to note that water quenched steel possesses the highest tensile strength values of $242.02 \mathrm{~N} / \mathrm{mm}^{2}$. But going by the values of the percentage elongation shown in Table 2, the ductility did not improve. Comparing the tensile strength, Red oil palm had a better effect on the low carbon steel during que nching $\left(166.32 \mathrm{~N} / \mathrm{mm}^{2}\right)$ to Palm kernel oil $\left(128.37 \mathrm{~N} / \mathrm{mm}^{2}\right)$ AS M (1995).

The yield strengths were eliminated in both Red oil palm and water quenched materials but for Palm kernel oil it reveals a good value of yield. There is however, general increase in value of the tensile strength of Red oil palm. It is important to note that between Red oil palm and Palm Kernel, Red-oilquenched steel possesses the highest strength values of $166.32 \mathrm{~N} / \mathrm{mm}^{2}$ ASM (1978). The impact strength of the heattreated specimen (using Red oil palm) was higher than all heat-treated and un-heat-treated materials. This strength is an indication of the level of toughness of the material. Results revealed that the as-quenched specimen of red oil palm possesses impact strength of 46.6J, is tougher than the Palmkernel-oil and water-quenched steels. The hardness values of the heat-treated specimens are generally higher than that of unheated-treated steel. In this case, the under indentation was used to evaluate hardness. The highest value of hardness 92.45HRB was obtained on water-quenched steel. This is in agreement with Grinshin (2016) who stated that water should be used in Plain Carbon Steel to have a high value of hardness. Red oil palm and Palm kernel quenched specimens produced $h$ ardness value of $79.5 \mathrm{HRB}$ and $61.2 \mathrm{HRB}$ respectively as show $\mathrm{n}$ in Table 2.

\subsection{Microstructure of Heat Treated Specimen}

The microstructure of the received low carbon steel shown in micrograph 1 and 2 showed the presence of pearlite and ferrite structure. The as quenched specimen in water, the microstruct ure of the low carbon steels shown in micrograph 3 and 4 the full transformation to cementite Specimen quenched in the Palm kernel oil (micrographs 7 and 8) reveal the formation of pearlite and retained austenite in varying proportions. The specimen quenched in Red oil palm for low carbon steel shows more of the austenite FAO (2015). This accounts for thehigher hardness induced in the quenched specimen i.e. com paring it with palm kernel oil. (Micrograph 5 and 6\}.

\section{CONCLUSION}

The properties of the heat treated low carbon steel compared favourably well when quenched with Red oil Palm and Palm Kernel Oil. The Low Carbon specimen has excellent value in terms of Hardness value, Tensile and Impact Strengths when quenched in Red oil palm. But Low carbon steel specimen quenched in Palm kernel oil was found to exhibit yield strength and elongation. The specimen quenched in Red oil palm has their yield points eliminated and the steel is found to be exhibiting higher level of toughness. Therefore, considering the vital mechanical properties, Red oil palm can be utilized as a quenching medium as compared with palm kernel oil in hardening process for Low carbon steels.

\section{ACKNOWLEDGEMENT}

The authors are grateful to Cecilia Titilope Aduke Isamotu (IYA OSUN) foundation for the moral and financial commitment towards the realization of this research work May God continue to rest your Soul until will meet to part no more.

\section{REFERENCES}

1. American Society of Metals (ASM), Metal Hand book. (1995). Material Part OH (pp. 822 - 873).

2. American Society of Metals (ASM), Metal Hand book. (1978). Material Part OH (pp. 15 - 35).

3. Bohumil, T., Steven, D., and Spanielka, J. S. (2012). "Effect of Agitation Work on Heat Transfer during Cooling in Oil Isorapid 277HM". Journal of Mechanical Engineering, Vol. 58. No. 2. (pp. 102106).

4. Cavaliere, P., Cerri, E., and Leo, P. (2016). "Effect of Heat Treatment on Mechanical Properties and Fracture Behavior of a Thixocast A356 Aluminum Alloy". Journal of Materials Science. Vol.39. (pp 1653 - 1658).

5. Ause, T. (2007). Investigation of Hardness and Impact Characteristics of quenched and cold treated ductile cast iron". Msc. Thesis, Department of Metallurgical Engineering, A.B.U, Zaria.

6. Beitz H. (2008). 'Non-combustible water based quenchants in forging shop for Automotive parts, latest development', In the first international Automo tive heat treatment conference. (pp. 106- 109). Puerto Vallarta, Mexico.

7. Rajan, T.V, Sharma, C.P.; and Sharma, A. (2014) Heat Treatment- Principles and Techniques, PrenticeHall of India Private Limited, New Delhi, India.

8. Thelning, K.E. (2017) Steel and Its Heat Treatment, 2nd ed. Butterworth, London, England, UK.

9. Ndaliiman, M.B (2006). Assessment of Mechanical Properties of Medium Carbon Steel under Different quenching Media (pp. 100 -104). 
10. Barley F.W.J (1971). Fundamentals of Engineering Metallurgy and Materials $5^{\text {th }}$ ed. (pp $42-53$ ).

11. Hassan, S. B, Balogun, S.O and Aigbodion, V. S. (2009) Hardening Characteristics of Medium Carbon SteelUsing Fresh Cassava Liquid Extract as Quenchants, Journal of Metallurgy and Materials Engineering, Vol4, No 2. (pp 55-610).

12. Food and Agriculture Organization of the United Nations (F.A.O) (2015). Processing of Red oil Palm, www.fao.org/docrep.

13. Food and Agriculture Organization of the United Nations (F.A.O) (2015). Processing of Palm kernel oil, www.fao.org/docrep.

14. Grinshin, S.A, and Churyukin, Y.N. (2016)

"Evaluation of the Cooling Capacity of Quenching Media Based on Water". Metal Sci. Heat Treat. Vol 28, No 10. (pp 744-5). 